\title{
Hibridaciones entre el turismo y la comedia en el tardofranquismo. A propósito de Manolo, la nuit (Mariano Ozores, 1973) y Tres suecas para tres Rodríguez (Pedro Lazaga, 1975)
}

Jorge Nieto Ferrando

Universitat de Lleida

Este capítulo, inscrito en el marco del proyecto de I+D La intersección entre cine y turismo: desarrollo bistórico-temático, claves culturales, políticas y económicas ${ }^{1}$ pretende aproximarse a la relación entre la comedia en el tardofranquismo y la transición y el turismo a través de las películas Manolo, la nuit (1973) y Tres suecas para tres Rodríguez (1975), dirigidas por dos de los cineastas más prolíficos, auténticos estajanovistas, del cine español del momento: Mariano Ozores y Pedro Lazaga respectivamente.

El primero, Mariano Ozores, provenía de una familia de comediantes, donde destacan sus hermanos José Luis y Antonio, y llegó a dirigir cerca de un centenar de películas - aproximadamente cuarenta entre 1973 y $1982-$, casi siempre en el ámbito de la comedia. Entre ellas son reseñables los títulos que cuestionarán y parodiarán los cambios políticos de la Transición desde posturas reaccionarias. A parte de Manolo la nuit, en lo referente a la temática turística dirige 40 grados a la sombra (1967) y En un lugar de la Manga (1970). Más amplio es el registro de Pedro Lazaga, que cultiva casi todos los géneros. También con cerca de un centenar de películas a sus espaldas - entre ellas algunas tan significativas para nuestros intereses como El turismo es un gran invento (1968), El abominable hombre de la Costa del Sol (1969) o Verano 70 (1970)-, lo más singular de este director catalán son sus vaivenes en la consideración crí-

HAR2011-27750/ARTE (Ministerio de Economía y Competitividad).

Smith, P. J. (2015). La comedia y el melodrama en el audiovisual iberoamericano. Editorial Iberoamer icana / Vervuert. https://elibro.net/es/ereader/udl/37069?page $=54$ 
tica. En los años sesenta será reivindicado por los denominados "marcianos", críticos que dan el salto de la cinefilia a la cinefagia desde la revista Film Ideal para aplicar a sus películas los supuestos críticos de André Bazin. Así, los planos que permiten mostrar la continuidad de las acciones, con lo que supone, siguiendo las reflexiones del reconocido escritor francés, de dar entrada a la ambigua realidad, la limitada utilización del montaje o la falta de control en la puesta en escena y, en definitiva, en la realización, lo convertirán para estos comentaristas desaforados en baluarte de la modernidad (Nieto, "Cine en papel" 104-116). Podría decirse que el realismo - ontológico - en las películas de Lazaga está más sustentado en su ritmo de producción - entre 1973 y 1979, fecha de su fallecimiento, por ejemplo, dirige cerca de una veintena de películas-, con lo que implica de dejar muchas cosas al azar en la puesta en escena, que en decisiones estéticas o estilísticas: es, por tanto, la deficiente realización lo que permite la presencia de la realidad en sus películas. Si bien muchas de estas particularidades continúan apreciándose en su cine de los años setenta, para entonces ya ningún crítico se atreve a defenderlo. En estos momentos el director navegará entre la comedia sexy en sus diferentes variantes - entre ellas la de tema político - al calor de la transición democrática.

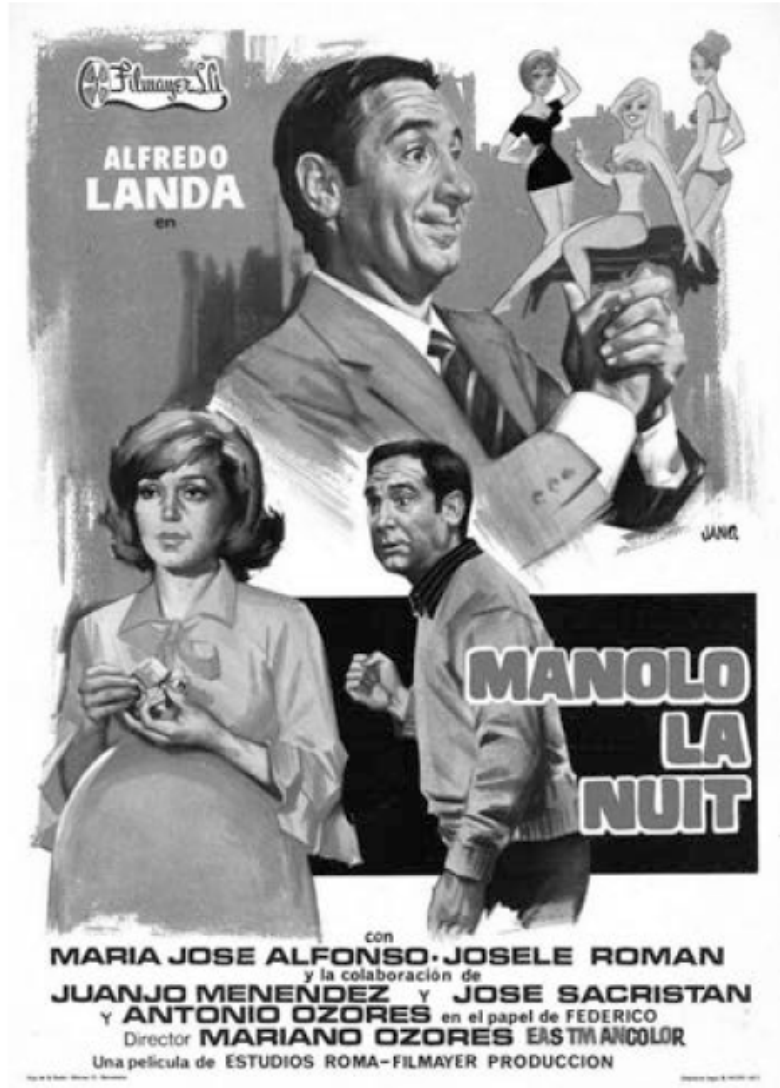

Cartel de Manolo, la nuit (Mariano Ozores, 1973) 
Tanto Manolo, la nuit como Tres suecas para tres Rodríguez se inscriben en los denominados "subgéneros", en concreto en el más prolífico y popular de todos, la "comedia sexy". Por películas de subgénero entenderíamos - más allá de la categorización dentro del propio género- aquellas que no tienen por referente las grandes tradiciones culturales y literarias propias del género, sino el cúmulo de formulaciones cinematográficas posteriores (Gubern 11-16). Ello conlleva cierta "degradación genérica", en este caso de la comedia, que conduce hacia las prácticas propias de la serie $\mathrm{B}$, con lo que supone de descuido en la factura formal, recurrencias temáticas, estereotipos, estructuras narrativas, situaciones dramáticas y personajes redundantes, etcétera. Justamente estas características, que en principio alejan las películas adscritas a la comedia sexy de todo canon articulado por criterios estéticos, han permitido someterlas a una lectura extrovertida, convertirlas en material de estudio sociológico. Dicha lectura, muchas veces limitada a los contenidos y con escasa atención a su puesta en forma, supone contemplarlas como muestra de las contradicciones ideológicas y morales del tardofranquismo y la transición, en especial las situaciones generadas por el conflicto entre la tradición y la modernidad en una sociedad en rápida transformación.

El choque entre ciertos valores considerados hispanos y las prácticas más relajadas introducidas en buena medida mediante el turismo, sobre todo en el ámbito de las costumbres sexuales, es empleado como recurso dramático en estas películas con efectos hilarantes, y su resultado suele ser la sexualización infantil -o mejor dicho "adolescente" - de las historias que narran, aunque siempre concluyan en el redil de la moral más tradicional. Como resume José Vanaclocha en "El cine sexy celtibérico",

del contraste entre incentivos eróticos visuales, chabacanos chistes verdes y obsesivas frases de doble sentido, por una parte, y de una moral tradicional mantenida a rajatabla, por otra, surge el carácter infantil, hipócrita, pornográfico y represivo del cine sexy celtibérico. Se ofrece así al espectador una válvula de escape frente al puritanismo represivo del sistema y se canaliza su rebeldía erótica hacia un terreno mental e ilusorio perfectamente controlable e inofensivo para el "establishment". Se le escandaliza y excita para terminar soltándole el consabido sermón cuaresmal sobre las miserias de los apetitos carnales (199-200).

En estas películas, añade Domènec Font, el coito ocupa el centro de la historia, aunque, a pesar de la ampliación de los límites de lo decible y lo visible en el cine de los años setenta, su representación acuda a la metáfora. Ahora bien, tras "la concupiscencia aparecerá el oropel de la moraleja, la conciencia marcada y delimitada por la ideología dominante que remeda el desorden y vuelve a colocar 
las cosas en su sitio: reproducción del aparato familiar, el matrimonio como institución, el orden y la moral establecidas contra toda suerte de estragos” (318).

Algunos autores en los últimos tiempos, sin embargo, han cuestionado si este regreso al orden, con la consabida moraleja, no se produce tras tantas contradicciones que acaban por invalidarlo. En su análisis de No desearás al vecino del quinto (1970), título inevitable a la hora de hablar de la comedia sexy, Barry Jordan rechaza la conexión directa entre cine de entretenimiento y los valores conservadores o reaccionarios, propia, según afirma, de la crítica de izquierdas de los años setenta - las aproximaciones de Vanaclocha y Font pueden adscribirse en esta-. Ello lo demuestra a través del análisis detallado de la película de Ramón Fernández. Si bien resulta difícil establecer una generalización de este tipo - crítica de izquierdas/rechazo del cine popular como trasmisor de la ideología conservadora o reaccionaria dominante-, más todavía teniendo en cuenta la difusión de los planteamientos cahieristas posteriores al sesenta y ocho en España, que se aplican tanto para cuestionar el cine comprometido políticamente como para "reivindicar" algunos géneros y directores muy populares ${ }^{2}$, Jordan abre una vía de análisis sugerente que puede dar resultados interesantes. Tal vez permita, como mínimo, superar el análisis de contenido reduccionista que habitualmente se ha aplicado a estas películas.

Una parte relevante de este "cine sexy celtibérico" tiene por tema el turismo. Es necesario aproximarse, aunque sea brevemente, a las diferentes relaciones entre el turismo y el cine bajo el franquismo para poder apreciar la singularidad de Manolo la nuit y Tres suecas para tres Rodríguez. Muchas de estas reflexiones han aparecido en los debates desarrollados en el marco del proyecto "La interacción entre el cine español y el turismo", además de en las publicaciones, congresos y otras actividades académicas generadas a partir de este (Del Rey Reguillo "Cine, imaginario” y “Turistas de película”).

En primer lugar, tendríamos las películas cuyo objetivo es la promoción del territorio, muchas de ellas de carácter documental. En cierta medida relacionadas con estas, y en segundo lugar, encontraríamos aquellas otras que, sin ser turísticas, presentan con claridad escenas y planos que no tienen otra finalidad que promocionar las ciudades - sus monumentos, calles, tradiciones o folclore- en las que desarrollan sus historias. Estos planos y escenas interrumpen

2 Véanse, por ejemplo, la demoledora crítica de Domènec Font al cine político de Francesco Rosi desde la revista Dirigido por o la revalorización del muy popular cine negro norteamericano desde las páginas de Film Guía (Nieto "Cine en papel”; Aranzubia y Nieto). 
impunemente en muchas ocasiones el flujo narrativo y se presentan de manera poco justificada, ya sea en películas ajustadas al cine mainstream o en las propuestas más innovadoras que intentan acercarse a los nuevos cines europeos en la década de los sesenta. En algunas películas llega a ser tan abrumadora la presencia de la vista turística que en su época los críticos llegaron a tildarlas de panfletos turísticos. Sucede, por ejemplo, en España otra vez (Camino) con las postales de Barcelona o las largas escenas de bailaoras junto a otras no menos significativas de lo que podríamos denominar "turismo etnográfico", muy influidas por el primer cine de Luis Buñuel (Nieto "Entre el turismo").

Esta abundancia de bailaoras y sobre todo las pasiones que rigen las relaciones entre los personajes conducen esta película - que narra, en principio, las vicisitudes memorísticas de un antiguo miembro de las Brigadas Internacionales durante la Guerra Civil de regreso a España a finales de los sesenta- por los caminos de la denominada "españolada". Este sería el tercer punto de conexión entre el cine y el turismo bajo el franquismo. La españolada - sus argumentos folletinescos regidos por las pasiones más viscerales, sus personajes reducidos al estereotipo: la gitana, la tonadillera, el bandolero, el torero, etcétera- se construye como imagen de lo español con gran atractivo en el interior, debido sobre todo a su arraigo en la cultura popular, pero busca fundamentalmente la proyección hacia el exterior jugando la baza del exotismo.

En la década de los cincuenta las instituciones franquistas recurrieron a los tópicos folclóricos románticos como reclamo para los turistas extranjeros (Moreno Garrido 210). Ello no se produjo sin desavenencias. De hecho, el propio Fraga desde el Ministerio de Información y Turismo señalará lo poco recomendable de "basar toda una industria turística en el cliché típico de pandereta y fiesta flamenca, en la imagen estereotipada e inauténtica de un país que, lejos de intentar parecerse a sí mismo, procura aproximarse a la idea preconcebida que los viajeros tienen de él" (ctd. Afinoguénova 44). En los debates teóricos y críticos sobre el cine también aparece la cuestión de la españolada. Ya en los años cuarenta, en revistas como Primer Plano o Radiocinema, puede apreciarse una clara conciencia del valor del cine en la creación de una "imagen de marca" positiva de la España franquista en el exterior, aunque todavía sea difícil apreciar su repercusión en la llegada de visitantes. El debate gira en torno a la conveniencia de seguir estimulando a través de las películas el estereotipo folclórico generado en Europa, y sin duda alimentado desde España, la españolada, o la más nacionalista "españolidad", que habrá de buscar sus temas en la religión, la historia de los grandes acontecimientos del pasado y su estética en la Generación del 98, primero, y aproximarse al realismo naturalista más tarde. 
Hablar de la españolada en el caso de la comedia sexy turística, y en concreto Manolo, la nuit y Tres suecas para tres Rodríguez, no es una digresión. De hecho, el concepto de españolada evoluciona en la década de los setenta hasta salirse de la iconografía folclórico-andalucista y englobar, como señala José Luis Navarrete, justamente las comedias subgenéricas. A ello hay que añadir que, si bien ya no aparecen bandoleros o tonadilleras en estas películas, motivos que le son propios como el honor, su defensa, la virilidad y la pasión irracional siguen planeando detrás de las acciones que narran. La nueva españolada desde finales de los años sesenta se caracteriza por "la proclamación de los valores tradicionales, arraigados en una moral rigurosa y conservadora, aunque esta estuviese escondida tras escenarios urbanos, seiscientos, minifaldas y suecas en biquini" (201).

En cuarto lugar, dentro de las relaciones entre cine y turismo bajo el franquismo, es fundamental analizar las políticas de promoción turística y el papel que el cine juega en ellas. Es indudable que se establece un vínculo entre el turismo y la política institucional en el campo de la comunicación con la creación del Ministerio de Información y Turismo en la década de los cincuenta. Si bien ambas funciones no interesaron del mismo modo, al menos en los primeros años de funcionamiento del ministerio (Moreno Garrido 195), el turismo forma parte de las estrategias propagandísticas de una dictadura que comienza a abrirse hacia el exterior en el marco de la reconfiguración de los ejes políticos internacionales, lo que permite pasar de ser sólo un régimen tolerado, a pesar de haber contado en su constitución con el apoyo de los fascismos, a gozar de la plena aceptación internacional. En el ámbito del cine puede detectarse cierta correlación entre las directrices expuestas en el Plan Nacional de Turismo de 1953, donde se exponen diferentes tipos de turismo - turismo histórico-artístico y folclórico, turismo de descanso, turismo deportivo y turismo de negocios - y las películas del mismo tema producidas en estos momentos (Del Rey Reguillo y Nieto). No podemos olvidar tampoco que la política cinematográfica de José María García Escudero desde la Dirección General de Cinematografía y Teatro poco tiempo más tarde, cuyo resultado fue la creación de un "nuevo cine" a la europea con repercusión internacional, tuvo como objetivo la generación de una imagen positiva de la España del momento, y que esta podía tener repercusión de una u otra manera en la llegada de visitantes.

Finalmente, dentro de esta sucinta parcelación de las relaciones entre cine y turismo bajo el franquismo encontraríamos las películas que tienen por tema el turismo, aunque permanezcan alejadas de cualquier intento promocional. El turismo es nada más - y nada menos - que una cuestión de candente actuali- 
dad, y por ello susceptible de protagonizar películas, como puede serlo la emigración a Europa, el desarrollo económico, el pluralismo político poco tiempo más tarde o la nueva apertura en materia de moral sexual. Esto ata las películas a su inmediato contexto, y con ello queda reforzado su valor sociológico. El turismo, como tema de actualidad, es susceptible de ser abordado desde diferentes géneros, aunque predomine en la comedia sexy por las posibilidades de explotar con efectos hilarantes las contradicciones entre la tradición y la modernidad que conlleva. Su público objetivo es el consumidor de cine popular español - "culturalmente poco desarrollado, localizado en provincias y ya, específicamente, en el área rural española”, afirmaba Domènec Font (320) - y a tenor de los datos de control de taquilla respecto a la "comedia sexy" sin duda lo alcanzó de sobra.

En esta última categoría situaríamos Manolo, la nuit y Tres suecas para tres Rodríguez, sin olvidar su relación con la españolada. En ambas películas el turismo, o más bien la turista, es un elemento de distorsión que enturbia la familia tradicional, aunque al final, una vez abandonadas las relaciones "ilegítimas" con las extranjeras, acabe siendo reforzada con la descendencia. En Tres suecas para tres Rodríguez, además, la representación del turista cambia de manera importante respecto a películas anteriores. Si en la década de los cincuenta el turista era presentado como un personaje ingenuo y en los sesenta como portador de unas costumbres y una cultura mucho más libre, en esta película, filmada una década después, las turistas son embaucadoras y utilizan la irreprimible tendencia a la infidelidad de los tres Rodríguez para sus negocios de tráfico de drogas.

Ambos filmes giran en torno al sexo, o más en concreto alrededor de la infidelidad masculina. En Manolo la nuit, Manolo (Alfredo Landa) trabaja en la costa mientras Susana (María José Alfonso), su esposa, vive en Madrid. El conocimiento de las aventuras sexuales de Manolo motiva que Susana le haga creer que está embarazada de otro hombre. Este es el detonante de la historia, y a partir de aquí una serie de enredos y malentendidos acabarán por demostrar que el "engaño" no es tal, que a pesar de todas los agravios de su marido la esposa se ha mantenido en el más estricto respeto al sacrosanto matrimonio, y al final esperará un hijo suyo. En la película la mujer - la mujer española- es dócil, afable, suave y fiel, pero capaz de todo cuando descubre la infidelidad de su marido, incluso de pagarle con la misma moneda. El hombre no concibe que la mujer pueda tener los mismos escarceos amorosos. En Tres suecas para tres Rodríguez el papel de la mujer española está igualmente adscrito a la familia tradicional. Ahora bien, si en la película de Ozores la infidelidad masculina se acaba 
ante la posibilidad de la femenina, en la de Lazaga es el deseo de conquistar a tres turistas extranjeras por parte de Paco (Tony Leblanc), Juan (Rafael Alonso) y Antonio (Antonio Ozores) el que actúa como detonante.

Hay que señalar que la infidelidad, las relaciones adúlteras, son el motivo que planea detrás de prácticamente todas las comedias populares del final del franquismo. En ellas aparecen tipos recurrentes, como el espabilado, el ingenuo o la mujer capaz de todo, además de los maridos escarmentados ${ }^{3}$, que también encontramos en ambas películas. Tanto Manolo como Paco aprenden una lección tras descubrir un engaño: el de su esposa el primero y el de las tres turistas, traficantes de drogas, el segundo.

Es destacable la influencia del sainete en ambas películas - en general en todas las adscritas a la comedia sexy turística-, tanto en la caracterización gruesa de los personajes, principales y secundarios, como en las estrategias narrativas y dramáticas. Respecto a los primeros nos encontramos con actores que vienen con su bagaje de tics, muecas y gestos exagerados, de gran eficacia cómica, repetidos en la interpretación de sus personajes de película en película, y cuyo "carácter" es ampliamente reconocible por el público: Alfredo Landa, Tony Leblanc o Antonio Ozores. Ozores, por ejemplo, secundario en ambos títulos, se caracteriza por su forma de hablar atropellada, cercana al tartamudeo, que va mucho más lejos de estas películas y repitió hasta la saciedad en buena parte de sus interpretaciones en cine y televisión. Como ha señalado Santos Zunzunegui a propósito de Alfredo Landa,

lo que está en juego con esta clase de actores es menos la admiración boquiabierta ante sus camaleónicas capacidades interpretativas que la asunción de ese contrato de confianza que se anuda calladamente entre el público y el comediante y que acaba convirtiéndose, a través de la continuidad y la permanente renovación de la fascinación ante lo mismo, en una familiaridad que, al final del camino, permite la transmutación de un cuerpo en un símbolo (183).

Es indudable que este contrato entre los cómicos y el espectador refuerza otro mucho más amplio, el propio pacto genérico, donde también son importantes los tipos - personajes - y motivaciones recurrentes ya mencionados, además de las situaciones reconocibles. La influencia del sainete es igualmente apreciable en los diálogos, en algunos casos atropellados, confusos - son

Tal como señala Álvaro del Amo en la Comedia cinematográfica española, las comedias de este periodo pueden dividirse prácticamente en dos grandes tipos: las de paletos y las de maridos escarmentados (35). 
frecuentes las escenas en las que los personajes parlotean indiscriminadamente $-\mathrm{y}$ con algunos gags verbales, y en las situaciones prolongadas en función de su comicidad, aunque ello entorpezca el flujo narrativo. Ambas características, además, son especialmente destacables en Tres suecas para tres Rodríguez, y coinciden en la penúltima escena con la muy sainetesca intervención de la autoridad pública para recomponer al orden en el enredo generado a lo largo de la película entre las "suecas", los Rodríguez y las esposas de estos últimos.

En Manolo la nuit, además de la presencia degenerada - conducida a la práctica subgenérica - del sainete, es destacable su tono paródico-satírico. Ello puede apreciarse fundamentalmente en el pregenérico. Este, que como tal marca la pauta estética y genérica de la película, comienza con una voz en over narrando las virtudes del sol en la península ibérica, ilustrada con imágenes de carácter referencial, contrapuestas a las situaciones climáticas del norte de Europa. Este contraste es lo que motiva la llegada de turistas a las playas del mediterráneo:

Han venido [continúa el narrador haciendo suyo el lema Spain is Different de algunas campañas promocionales de los años sesenta] porque España es diferente, y aquí encontrarán el sol, la paella, las corridas de toros y también, por qué no decirlo, algunas vienen buscando el romance, la aventura. Desde Rodolfo Valentino, los latin lovers tenemos mucho cartel, y ustedes perdonen la inmodestia.

Todo este parlamento viene ilustrado por hombres en bañador, de aspecto nórdico y atractivo, caminando delante de numerosas turistas que muestran con claridad su desidia e incluso rechazo.

Claro que sobre gustos no hay nada escrito. Por eso, el que levanta más admiración a su paso es ese colosal producto que salió del cruce de dos pueblos rudos y primitivos: los celtas y los iberos. Nos referimos al racial celtíbero español, que en este caso se llama Manolo.

La actitud de las bañistas cambia de manera considerable ante la presencia de Manolo, encarnado por el poco agraciado físicamente Alfredo Landa. Toda la planificación de esta escena está articulada mediante campo/contracampo, lo que permite, al mostrar la reacción de admiración y deseo entre las turistas despertada por Manolo antes de su aparición en campo, incrementar el efecto cómico sustentado justamente en la sorpresa que provoca apreciar el contraste entre el cuerpo de Landa, los cuerpos esculturales de los bañistas que han des- 
filado con anterioridad delante de las turistas e incluso la comparación con los latin lovers y Rodolfo Valentino.

Esta escena es clave para entender que, al menos en esta película, el personaje interpretado por Alfredo Landa no es tanto un alter ego del "españolito de a pie" - en ocasiones se ha afirmado esto al hablar de las comedias que protagonizócomo su parodia y la de al menos dos estereotipos interrelacionados: uno ideado por el culto a las stars (el latino seductor) y, ligado a este, otro que podríamos situar en el ámbito de la españolada, el donjuán. Aquí reside en buena medida la comicidad de la película, en la atribución al personaje de una serie de características que entran en clara contradicción con su aspecto físico. Evidentemente, el turismo, reducido a la modalidad de "turismo sexual", también se ve afectado por la parodia.

En Tres suecas para tres Rodríguez las tuercas de la comedia turística se aprie$\tan$ hasta salirse de rosca. De hecho, la película hace buenas las ya viejas propuestas de Jean Louis Comolli y Jean Narboni en su "Cinéma/Idéologie/Critique", publicado en Cahiers du cinéma a finales de los años sesenta y de enorme impacto en la crítica de su momento, cuando señalaban que en ocasiones películas inscritas dentro del cine hegemónico contienen tantos elementos subversivos que se traicionan a sí mismas, que justamente acaban por cuestionar la ideología que sustentan. A pesar de ser una comedia sexy turística, con buena parte de los elementos propios de esta, lo singular de la planificación, de los movimientos de cámara, utilizando en numerosas ocasiones la cámara en mano, o las angulaciones de las tomas hacen evidente la existencia del dispositivo filmador y, con ello, rompen la ilusión diegética. A esto hay que añadir los grandes problemas de verosimilitud de la historia narrada, tanto por la interpretación de los personajes como por las situaciones insólitas - donde no es menos singular el hecho de convertir a todas las extranjeras en suecas o de que Adela (Florinda Chico) esté embarazada a pesar de su edad-. El regreso al orden, a la reafirmación de las relaciones sexuales regladas por el matrimonio, se produce después de un tránsito por infinidad de incoherencias, contradicciones y rupturas que cuestionan, a veces por exasperación, las convenciones de la comedia sexy e incluso las del Modelo de Representación Institucional en el que están sustentadas.

Pueden afirmarse que el prolífico Lazaga, a pesar de haber pasado ya la fiebre marciana que le llevó a ocupar un efímero lugar destacado en el canon cinematográfico de los años sesenta, seguía siendo en la década de los setenta uno de los cineastas españoles más singulares, muy a su pesar (o no).

Lo que en Manolo la nuit es parodia del turismo en Tres suecas para tres Rodríguez llega a ser una puesta en cuestión de la comedia sexy turística. Tanto una como otra hunden sus raíces en la comedia española previa, sobre todo la 
influida por el sainete, y en algunos tópicos de la españolada, como el donjuanismo en Manolo la nuit, conduciéndolos a la degradación subgenérica. Su conclusión es conservadora, incluso reaccionaria. Proponen un regreso al orden de la familia patriarcal, asociado en principio al franquismo, y con este apuestan con decisión por la tradición frente a la modernidad representada por lo foráneo. Ahora bien, un análisis detenido - en la línea del realizado por Barry Jordan-puede mostrar que la reafirmación de este orden no se hace sin algunas contradicciones singulares; incluso que la reiterada ruptura de la ilusión diegética, como mínimo en la película de Lazaga, dificulta su condición de vehículo de trasmisión de la ideología dominante, con frecuencia atribuida a este cine.

Manolo la nuit y Tres suecas para tres Rodríguez explotan la única vertiente de las relaciones entre cine y turismo que no tiene por destinatario prioritario el público foráneo. Su función no es cautivar mostrando excelencias paisajísticas y folclóricas, halagar la imaginación extranjera con estereotipos reconocibles y románticos o generar una imagen atrayente de marca de la España tardofranquista. Ambas películas buscan al público español, al espectador "de cine de barrio" que disfruta de una comedia con elementos - personajes, situaciones, estrategias narrativas, etcétera- muy reconocibles.

\section{BiBLIOGRAFÍA}

Afinoguénova, Eugenia. "La España negra en color: el desarrollismo turístico, la auto-etnografía y España insólita (Javier Aguirre, 1965)”. Archivos de la Filmoteca 69 (2012).

Aмо, Álvaro del. Comedia cinematográfica española. Madrid: Alianza Editorial, 2009.

Aranzubia Cob, Asier y Nieto Ferrando, Jorge. "Un idilio efímero o de cómo el influjo de la teoría renovó la crítica cinematográfica española en los años setenta”, Secuencias 37 (2014).

Camino, Jaime, dir. España otra vez, Pandora, 1968.

Comolli, Jean Louis y Narboni, Jean. "Cinéma/Idéologie/Critique". Cabiers du cinéma 216-217 (1969).

- ed. Turistas de película. Sus representaciones en el cine hispánico. Madrid: Biblioteca Nueva, 2013.

- y Nieto Ferrando, Jorge. "Transiciones del turismo en el cine español de ficción de los años cincuenta y sesenta”. En Actas del Congreso Internacional Spanish Cinema. Madrid: Universidad Carlos III, 2013. 
Fernández, Ramón, dir. No desearás al vecino del quinto, Atlántida Films, 1970. Font, Domènec. "Francesco Rosi”. Dirigido por, 23 (1975). 1-17.

- Del azul al verde. El cine español durante el franquismo. Barcelona: Avance, 1976.

Gubern, Román. "Prólogo". Cine español, cine de subgéneros. Ed. Equipo Cartelera Turia. Valencia: Fernando Torres, 1974. 11-16.

Hernández Ruiz, Javier y Pérez Rubio, Pablo. Voces en la niebla. El cine durante la transición española (1973-1982). Barcelona: Paidós, 2004.

JoRDAN, Barry: "Revisiting the 'comedia sexy ibérica': No desearás al vecino del quinto (Ramón Fernández, 1971)”, International Journal of Iberian Studies 15-3 (2003). 167-186.

- "La comedia sexual española de principios de los setenta y el film reaccionario". Res Publica 13-14 (2004). 287-296.

Lazaga, Pedro, dir. El turismo es un gran invento, Pedro Masó/Filmayer Producción, 1968.

- El abominable hombre de la Costa del Sol, Pedro Masó/Filmayer Producción,1969.

- Verano 70, Pedro Masó/Filmayer Producción, 1970.

- Tres suecas para tres Rodríguez, Argumento Films/Rafael Vázquez Fajardo, 1975.

Martínez Puche, Antonio; Martínez Puche, Salvador y Prieto Cerdán, Antonio, ed. Territorios de cine. Desarrollo local, tipologías turísticas y promoción. Alicante: Universidad de Alicante, 2012.

Monterde, José Enrique. Veinte años de cine español (1973-1992). Un cine bajo la paradoja. Barcelona: Paidós, 1993.

Moreno Garrido, Ana. Historia del turismo en España del siglo XX. Madrid: Síntesis, 2007.

Navarrete, José Luis. Historia de un género cinematográfico. Madrid: Quiasmo, 2009.

Nieto Ferrando, Jorge. Cine en papel. Cultura y crítica cinematográfica en España (1962-1982). Valencia: Ediciones de la Filmoteca, 2013.

- "Entre el turismo y el aperturismo. A partir de la España otra vez (1968) de Jaime Camino”. Turistas de película. Ed. Rey Reguillo, Antonia del. Madrid: Biblioteca Nueva, 2013.

Ozores, Mariano, dir. 40 grados a la sombra, Productores Exhibidores Films,1967.

- En un lugar de la Manga, Arturo González Producciones Cinematográficas/José Frade Producciones Cinematográficas, S.A., 1970. 
- Manolo, la nuit, Filmayer Producción, 1973.

Rey Reguillo, Antonia del, ed. Cine, imaginario y turismo. Estrategias de seducción, Valencia: Tirant lo Blanch, 2007.

Ríos Carratalá, Juan Antonio. Lo sainetesco en el cine español. Alicante: Universidad de Alicante, 1997.

VV. AA. "Cine negro". Film Guía 15 (1977). 35-47.

Vanaclocha, José. "El cine sexy celtibérico”. Cine español, cine de subgéneros. Ed. Equipo Cartelera Turia. Valencia: Fernando Torres Editor, 1974. 195-284.

Zunzunegui, Santos. Historias de España. De qué hablamos cuando hablamos de cine español. Valencia: Ediciones de la Filmoteca, 2002. 